\title{
EPIDEM: A Mobile Application to Contain Coronavirus Disease 2019
}

\author{
Goetz Robert Uwe Grosche1, Anna Katrina Javier Bolivar ${ }^{2}$ \\ ${ }^{1}$ I-Optic Computing, Wollongong, Australia \\ ${ }^{2}$ Independent Researcher, Quezon City, Philippines \\ Email: rob@i-optic.com, akatrina.jbolivar@gmail.com
}

How to cite this paper: Grosche, G.R.U. and Bolivar, A.K.J. (2020) EPIDEM: A Mobile Application to Contain Coronavirus Disease 2019. E-Health Telecommunication Systems and Networks, 9, 49-59. https://doi.org/10.4236/etsn.2020.94004

Received: November 3, 2020

Accepted: December 12, 2020

Published: December 15, 2020

Copyright () 2020 by author(s) and Scientific Research Publishing Inc. This work is licensed under the Creative Commons Attribution International License (CC BY 4.0).

http://creativecommons.org/licenses/by/4.0/ (c) (i) Open Access

\begin{abstract}
With the spread of COVID-19 across the globe, almost 33 million people became sick and almost 1 million have died (WHO). The government of the Philippines, along with the government of other countries declared movement restrictions or lockdown in the attempt to contain the virus. This resulted in loss of job and economic breakdown. The Philippines, in particular, experienced the longest and strictest lockdown. As a down side, a lot of people have lost their jobs and the country is currently facing economic recession. With the aim of containing the virus to reopen the economy, a team of experts developed a mobile application called EPIDEM. The application is available for both Android and Apple smartphones. With the use of EPIDEM, lay people can monitor their infection risk for COVID-19 and isolate themselves or get themselves tested when infection risk is high. Users can also monitor the health risk of other people that they come in contact with, so they can decide if meeting them is safe or risky. Further, the application provides a monitoring map that shows the area that is safe from COVID-19 and area where a possible outbreak might occur. The monitoring map will be helpful to both lay people, so they would know the places to avoid and to government officials, so they can quickly respond to outbreak. The teams of developers are recommending the nationwide implementation of EPIDEM to help contain the COVID-19 outbreak in the country. The application is not a new strategy of containment. Instead, it's a better wheel that utilizes advanced technology to execute the manual containment strategies that are already being implemented in the country.
\end{abstract}

\section{Keywords}

COVID-19, Coronavirus Disease 2019, Mobile Application 


\section{Introduction}

According to the World Health Organization (WHO), COVID-19 is an infectious disease caused by a recently discovered coronavirus, a type of virus that causes respiratory infections. The virus was first discovered after it caused an outbreak, in December 2019. The disease is commonly characterized by dry cough, fever, and tiredness. Other less common symptoms include sore throat, diarrhea, nasal congestion, headache, loss of taste or smell, and discoloration of fingers or toes.

While some people become infected while only manifesting very mild symptoms, other people become seriously ill and experience difficulty in breathing. People from the older age group and those with underlying medical conditions are at higher risk of being seriously ill. However, it is important to note that anyone can be infected with the virus and suffer from severe symptoms.

The virus that causes COVID-19 can be transmitted from person to person via droplets that are expelled by infected people when they cough, sneeze, or talk. Nearby people can breathe in the droplets and become infected. People can also be infected by touching surfaces contaminated with the virus and getting their hands near their mouth or nose. Transmission can be prevented by physical distancing or maintaining a one-meter distance from one another and by frequent handwashing.

Community spread or community transmission is apparent in many affected areas, where the large number of cases can no longer be linked to a confirmed case. In some instances, people also become infected without even knowing how or where they got the virus. As the virus infects more and more people across the globe, the WHO, on 11 March 2020, declared COVID-19 as a pandemic.

\subsection{Global Scenario: COVID-19 Situation and Economic Implication}

Based on the WHO COVID-19 Dashboard as of 30 September 2020, more than 33 million people have contracted the disease and more than 1 million have succumbed to it. The United States of America has reported the highest number of cases at 6,703,698 and highest number of deaths at 198,094 [1].

With the rapid spread of COVID-19 across the globe, countries were forced to impose strict movement restrictions to control its spread, which resulted in impaired economic activity. And as the number of affected people continues to increase, the damage to the economy continues to intensify. According to the World Bank, this is by far the largest economic shock that the world has suffered in decades [2]. The Asian Development Bank (ADB) estimated a global loss of $\$ 5.8$ trillion to $\$ 8.8$ trillion because of the pandemic.

\subsection{Local Scenario: COVID-19 Situation and Economic Implication}

In the Philippines, at least 309,000 people have been reported to have the disease 
and more than 5000 have died [1]. With the intention of halting the spread of the disease, strict lockdowns were implemented in various provinces and cities across the country. The Philippines experienced the world's longest and strictest lockdown in relation to the current pandemic. This resulted to the national economy falling to recession for the first time in 29 years. The negative impact to the economy could continue with the continuous movement restrictions and the record-high unemployment is still expected to climb up as the number of COVID-19 cases continues to rise [3].

According to $\mathrm{ADB}$, the economy in areas with continuous outbreak and strict lockdowns will suffer the most. The economic cost could be lessened by containing the pandemic. A quick and effective containment will enable the economy to recover faster [4]. If the country would not be able to contain the virus and would continue to impose movement restrictions, the Philippines' economic recovery may be the slowest in the Southeast Asia [3].

\subsection{Use of Mobile Application to Contain COVID-19}

With the attempt to contain COVID-19, mobile health applications have been developed and utilized in different parts of the world. These mobile applications aided the public health system in symptoms checking, health information dissemination, contact tracing, and providing training tools for healthcare providers. However, only few applications have overlapping functions such as symptoms checker, contact tracing, and information dissemination functions. According to one study, in order to encourage wide use of a mobile application, it has to feature several important functions that are consolidated into a single system [5].

\section{EPIDEM Mobile Application}

Digital technology is an important component of a comprehensive response for an outbreak or pandemic like COVID-19. It can help reduce the impact of the pandemic to humans and to the economy as well [6]. It is in that light that EPIDEM was developed. The mobile application was also aligned with the COVID-19 technology needs identified by the UNDP in their COVID-19 Detect and Protect Challenge. They launched the \#COVID19 Detect Protect to encourage developers to create an open-source technology that developing countries can use in their fight against the current pandemic.

EPIDEM was developed by a team led by Rob Grosche, the Chief Technology Officer (CTO) of I-optic Computing. Although based in New South Wales, Australia, Rob Grosch has close family members living in the Philippines. This mobile application is one of Rob's contribution to the country as we try to combat COVID-19.

\subsection{Rationale}

Big pharmaceutical companies across the globe are now diligently conducting 
clinical trials for the development of an effective vaccine against COVID-19. While the whole world is waiting for that big breakthrough, people have stayed indoors and economy has greatly stopped. According to the Social Weather Station (SWS), the number of Filipinos who were experiencing hunger doubled because of the lockdown that had to be imposed because of the pandemic [7]. Further, the ADB reported that the Philippines can lose 87,000 to 252,000 jobs because of the COVID-19 outbreak [8]. The situation may continue to worsen as COVID-19 continues to be transmitted in the community.

Epidemiologists across the globe are promoting "containment" as a key strategy to prevent community transmission of COVID-19 [9]. A study showed that containment measures being implemented in different countries are very effective in flattening the pandemic curve. Further, it was highlighted that effectiveness was enhanced when the containment measures were implemented quickly [10].

EPIDEM is a mobile application that aims to help contain COVID-19 in the Philippines by using digital technology. It is a very accessible system, available for Android and Apple smartphones, that would allow individuals to monitor their health risk and also allow users to know who among their contacts have COVID-19 symptoms. With this important information at hand, people can self-isolate and similarly, they can monitor their families and peers if they are also doing proper self-isolation. This then prevents further transmission of COVID-19.

The application also facilitates the monitoring of the pandemic situation in any geographic area of the country. Government officials have access to real-time or live data and can quickly see a potential or growing outbreak. The access to metadata would also be helpful should they need evidence for decision making (e.g. resource allocation, close monitoring). The application can also be used for contact tracing. EPIDEM is a better wheel that will make the current manual strategies of identifying suspected cases, contact tracing, and surveillance faster by allowing everyone to have access to real-time data.

\subsection{Users}

Anyone can use EPIDEM. Lay people and government officials will both benefit from its use. The application has the capacity to hold data for as many as 12 billion people. The software can be downloaded in a smartphone or a computer. It has a very friendly user interface that is not intimidating to technologically challenged people.

\subsection{Features}

The application has several features that can help in containing the virus in the country. As mentioned, both lay people and health officials can benefit from the use of the app. EPIDEM has features that are accessible only to lay people, while there are features that are accessible to identified health officials. 


\subsubsection{Personal Information and Location}

Once the application has been successfully installed on a smart phone or computer, a form will appear on the screen asking for some information as shown in Figure 1.

Those with asterisks $\left(^{*}\right)$ are required fields while those without are optional fields. It is however, encouraged that users provide information on the optional fields as well because these are important information that would enable health officials to contact with them should the need arise. The location of the user will be automatically identified by the system. Using GPS or IP address, the system would be able to determine the estimated location of the user using latitude and longitude. The name and mobile number will be useful in cases of contact tracing, while the location of the user will be used for the outbreak mapping.

\subsubsection{Infection Risk Passport}

The infection risk passport is a significant way to implement the containment strategy that EPIDEM aims to facilitate. The COVID-19 infection risk of an individual is assessed on daily basis using a scoring system that is based on his answers to the questions in Table 1.

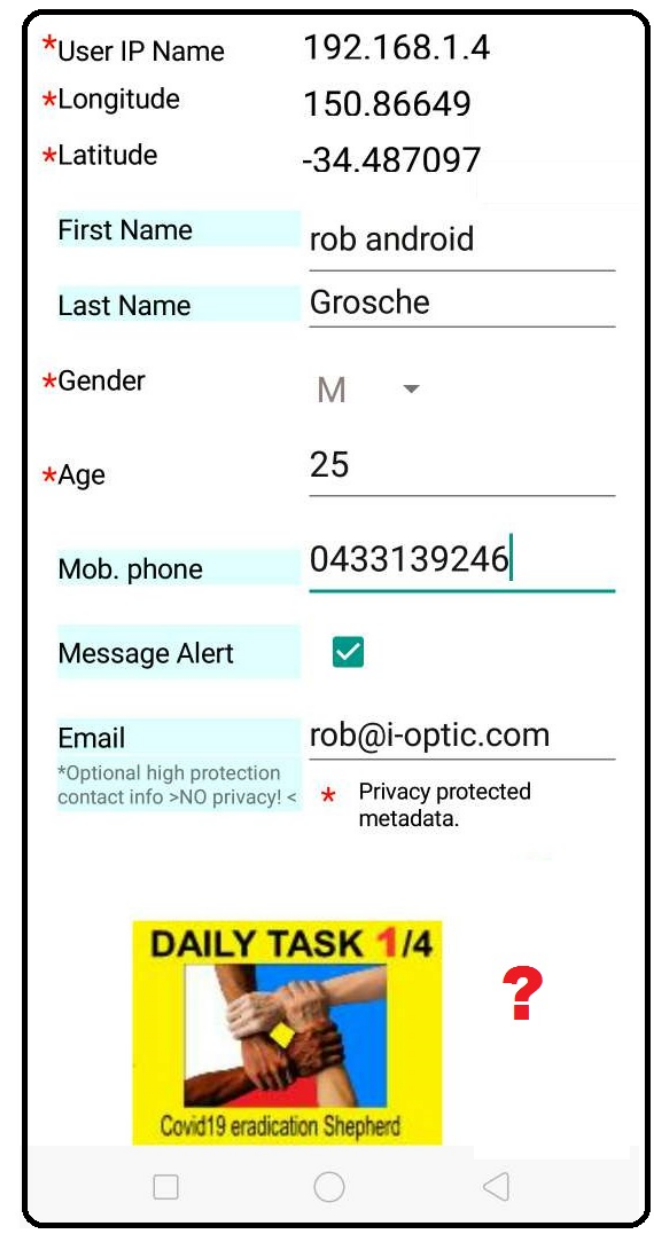

Figure 1. Location and personal information page. 
Table 1. COVID-19 risk monitoring questions.

\begin{tabular}{|c|c|}
\hline Question & Response options \\
\hline Do you have a fever? & Yes/No \\
\hline Is your fever getting better or worse? & Better/Worse \\
\hline Describe the severity of your fever? & Line number from 0 to 10 \\
\hline Select your current temperature & Line number from 35 to 40 degrees \\
\hline Do you have a persistent dry cough? & Yes/No \\
\hline Rate the severity of your cough? & Line number from 0 to 10 \\
\hline Is your cough getting better or worse? & Better/Worse \\
\hline Do you cough mucus from your lungs? & Yes/No \\
\hline Please rate the severity of your mucus of phlegm & Line number from 0 to 10 \\
\hline Is your mucus improving or getting worse? & Better/Worse \\
\hline Do you have a sore throat? & Yes/No \\
\hline Do you have a newly acquired shortness of breath? & Yes/No \\
\hline Do you feel abnormally fatigued? & Yes/No \\
\hline Are your joints unusually painful? & Yes/No \\
\hline Is your skin unusually pale or clammy? & Yes/No \\
\hline $\begin{array}{l}\text { Do you have any of these symptoms? } \\
\text { Headache, muscle pains, runny nose, nausea, vomiting } \\
\text { or diarrhea, fatigue, loss of sense or smell, altered sense } \\
\text { of taste, jaw pain, chest pain, feeling unusually cold, } \\
\text { new pain which prevents walking }\end{array}$ & Yes/No \\
\hline Infected with coronavirus 2019 before? & Yes/No \\
\hline
\end{tabular}

The application will show the questions one a time. The user has to provide an answer before he can proceed to the next question. Once the user has provided all the information, the application will provide a summary of his responses to confirm if they're correct and ready for submission. Once the user confirms, the system submits the data to the cloud database to be analyzed. After which, and the system generate the user's current infection risk through an infection passport (see Figure 2). 
In relation to the user's current infection risk, the system will also provide a relevant "advice" as to what the user should do. These advices were prepared and reviewed by healthcare professionals. Table 2 is a table of the advices that the system will provide depending on his current infection risk. Note that the infection risk has color codes. This coding system will be used in the outbreak mapping, which will be described later.

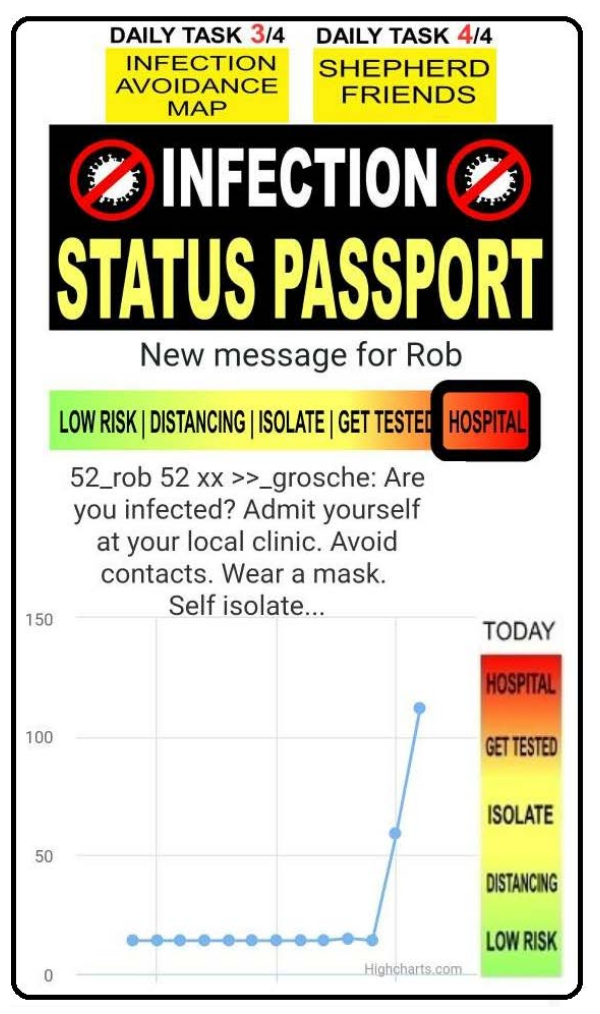

Figure 2. Infection status passport page.

Table 2. Health advices according to COVID-19 risk.

\begin{tabular}{|c|c|c|c|}
\hline Infection risk & Advice & Infection risk & Advice \\
\hline Low risk & $\begin{array}{l}\text { View your outbreak risk } \\
\text { HealthMap above before } \\
\text { travelling to keep your family } \\
\text { and our community safe. }\end{array}$ & Get tested & $\begin{array}{l}\text { Get tested. You are at risk } \\
\text { of being infected. Avoid } \\
\text { contacts. Self-isolate to } \\
\text { protect your family and } \\
\text { community. Wear a mask. }\end{array}$ \\
\hline Distancing & $\begin{array}{c}\text { Be serious about keeping a big } \\
\text { social distance. Do not travel } \\
\text { through crowded places. } \\
\text { Wear a mask. }\end{array}$ & Hospital & $\begin{array}{l}\text { Are you infected? Admit } \\
\text { yourself at your local clinic. } \\
\text { Avoid contacts. Wear a } \\
\text { mask. Self-isolate. }\end{array}$ \\
\hline Isolate & $\begin{array}{l}\text { Get tested and isolate for } \\
\text { your and your family's safety. } \\
\text { Isolate. Wear a mask. }\end{array}$ & & \\
\hline
\end{tabular}


Once the result of COVID-19 test turns out positive, health workers can activate a logo that says "COVID-19 Positive Infectious" (Figure 3). Only authorized health workers can activate and deactivate this logo, based on the user's COVID-19 test result.

The infection risk passport is a self-monitoring tool that can be used in the grassroots. People can assess their own risk and be active and vigilant to isolate or seek medical help when necessary. Similarly, front-line health workers can be protected by checking the infection risk passport of a patient prior to any examination. Further, the infection risk passport, as the name implies, can be used as a passport when meeting with other people or entering an establishment (i.e. schools, houses, malls, restaurants, grocery stores, hospitals). We protect ourselves by checking the infection risk of the people we come into contact with; we protect other people by following the advice given when we have symptoms; we protect the community by ensuring that only low-risk individuals are allowed to roam around establishments.

\subsubsection{Circle of Trust}

It is a common knowledge that COVID-19 spreads from person-to-person. In this specific feature of the application, users would be able to see the infection risk of the people they commonly interact with. By identifying people that you commonly come in contact with, users can link with them using EPIDEM to build a "circle of trust", which is a network of healthy individuals who are socially connected. The circle of trust becomes a self-monitoring group, where all members are made capable of monitoring the infection risk of one another. It is almost like a surveillance system in a smaller community.

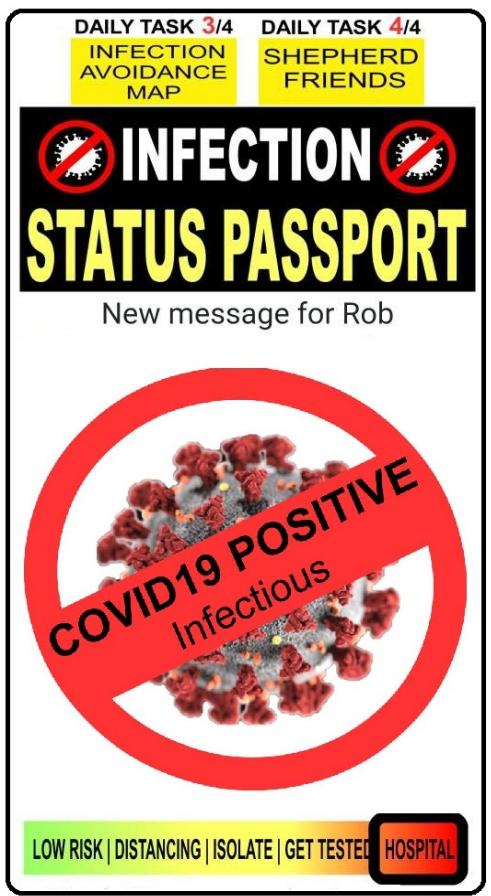

Figure 3. Infection status page of a COVID-19 positive person. 


\subsubsection{COVID-19 Monitoring Map}

In order to contain COVID-19, it is very important to halt the spread of a potential outbreak. EPIDEM features a COVID-19 monitoring map that would serve as a surveillance system and can detect the start of a potential outbreak. The map can be used from small-scale (circle of trust) to big-scale (nationwide) monitoring. EPIDEM can generate a color-coded map of a user's circle of trust and can also generate a color-coded map of any geographic location that is identified by health officials (Figure 4). The color code shown in the map corresponds to the color code used in the infection risk passport. A map showing an all green spots indicates a safe area. People can safely go to that area for any important business that they might have. On the contrary, a map showing a lot of red spots indicate that a lot people in that area are COVID-19 positive. This shows the area that needs to be avoided.

The COVID-19 monitoring map is a great tool to halt the spread of potential outbreak. Further, it provides real-time evidence that health officials can use for decision making.

\subsubsection{Metadata}

Health officials can access the EPIDEM's metadata. This is a huge collection of all the data gathered from all EPIDEM users across the country. Such data are made available to health officials, so they can respond quickly when needed. This will enable them to easily get in touch with people who need to be monitored because of symptoms presented and can quickly communicate with identified people for contact tracing. Most importantly, metadata can be used as bases for decision or policy making.

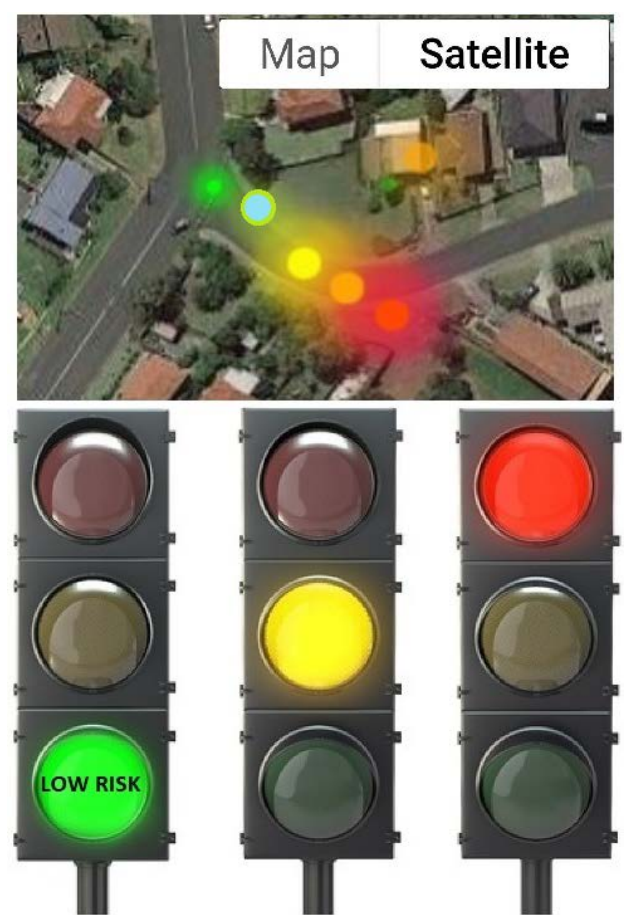

Figure 4. Color-coded monitoring map. 
In the future, the metadata provided by EPIDEM can also be used for researches related to COVID-19 in the community or workplace setting.

\subsection{Cost Implications}

The EPIDEM is a low-cost mobile application that can be used across the whole Philippines. The developers made it very affordable, especially for developing countries. The cost implications would include set-up, customization, support, security, and data storage. The plan is to recode the system in an open source platform to further reduce the cost.

\subsection{Privacy}

The personal data that will be shared by the users will be accessible only among health officials. As previously mentioned, the contact details such as name and mobile number would be used for contact tracing. The bulk of data that would be collected in the system would be stored in Google cloud and will only be available to the technical support team and health officials. Should researches request for access to the data, the permission would have to go through the health officials. To further ensure the privacy of the data, security level clearances can be put in place.

\section{Recommendations}

A nationwide implementation of EPIDEM in the Philippines is highly recommended. With proper use, this mobile technology can have a significant impact in containing COVID-19 in the country.

EPIDEM can protect the community in several ways. Application users would be able to know when they need to self-isolate to protect other people and stop spread of the disease. Users can also protect themselves by looking at other's infection risk passport and outbreak map to know which people and places to avoid. Front-line health workers are better protected because of the infection risk passport. Health officials have easy access to information needed for contact tracing (e.g. which people needs to be traced and their contact information). Health officials have real-time data available for their decision making and resource allocation. Our team believes that each feature, when used altogether, has a synergistic effect in the containment of COVID-19. Eventually, it would be safer to open industries with minimal risk among the workforce and other members of the community, and economy would be able to rise again.

\section{Acknowledgements}

The authors would like to acknowledge the expertise shared by the whole team who diligently and passionately put in effort for the development of the EPIDEM. Specifically, the authors would like to thank the following people: VeitGrosche, Layla McNeil, Haris Fawad, Muhammad Waseemwalich, Mark Kwagbedzie, and Tapan Kumar. We would also like to acknowledge all the hard-working pro- 
grammers who helped in the development of EPIDEM.

\section{Conflicts of Interest}

The authors declare no conflicts of interest regarding the publication of this paper.

\section{References}

[1] World Health Organization (2020) Q\&A on Coronaviruses (COVID-19). https://www.who.int/emergencies/diseases/novel-coronavirus-2019/question-and-a nswers-hub/q-a-detail/q-a-coronaviruses

[2] The World Bank (2020) The Global Economic Outlook during the COVID-19 Pandemic: A Changed World.

https://www.worldbank.org/en/news/feature/2020/06/08/the-global-economic-outlo ok-during-the-covid-19-pandemic-a-changed-world\#: :text=Businesses\%20might \%20find\%20it\%20hard,by\%20almost\%208\%25\%20in\%202020

[3] Al Jazeera (2020) Philippine Economy Posts Its Biggest-Ever Quarterly Plunge. Al Jazeera Media Network.

https://www.aljazeera.com/economy/2020/8/6/philippine-economy-posts-its-bigges t-ever-quarterly-plunge

[4] Asian Development Bank (2020) COVID-19's Global Economic Impact Could Reach \$8.8 Trillion-ADB.

https://www.adb.org/news/videos/covid-19-s-global-economic-impact-could-reach8-8-trillion-adb

[5] Davalbhakta, S., Advani, S., Kumar, S., Agarwal, V., Bhoyar, S., Fedirko, E., Agarwal, V., et al. (2020) A Systematic Review of Smartphone Applications Available for Corona Virus Disease 2019 (COVID-19) and the Assessment of Their Quality Using the Mobile Application Rating Scale (MARS). Journal of Medical Systems, 44, Article No. 164. https://link.springer.com/article/10.1007/s10916-020-01633-3 https://doi.org/10.1007/s10916-020-01633-3

[6] Budd, J., Miller, B., Manning, E., Lampos, V., Zhuang, M., Edelstein, M., McKendry, R., et al. (2020) Digital Technologies in the Public-Health Response to COVID-19. Nature Medicine, 22, 1183-1192.

https://www.nature.com/articles/s41591-020-1011-4 https://doi.org/10.1038/s41591-020-1011-4

[7] Inquirer.net (2020) Number of Hungry Filipinos Almost Doubles as Pandemic Rages-SWS.

https://newsinfo.inquirer.net/1279086/number-of-hungry-filipinos-almost-doublescovid-19-pandemic-rages-sws

[8] Business and Human Rights Resource Center (2020) Philippines: ADB Projects Massive Job Loss across 5 Sectors Due to Covid-19 Outbreak.

https://www.business-humanrights.org/en/latest-news/philippines-adb-projects-ma ssive-job-loss-across-5-sectors-due-to-covid-19-outbreak/

[9] Walensky, R. and del Rio, C. (2020) From Mitigation to Containment of the COVID-19 Pandemic. Journal of American Medical Association, 323, 1889-1890.

https://jamanetwork.com/journals/jama/fullarticle/2764956 https://doi.org/10.1001/jama.2020.6572

[10] Deb, P., Furceri, D., Ostry, J. and Tawk, N. (2020) The Effect of Containment Measures on the COVID-19 Pandemic. International Monetary Fund Working Paper. https://doi.org/10.5089/9781513550268.001 